UDC 664

DOI: $10.15587 / 2706-5448.2021 .242333$

Article type «Reports on Research Projects»

\title{
Feifei Shang, STUDY ON THE OPTIMIZATION OF SPRAY Tetyana Kryzhska, DRYING PROCESS FOR ARECA TARO POWDER Zhenhua Duan WITH MICROCYSTALLINE CELLULOSE
}

Starch is a product of intensive processing of agricultural products. During the processing of plant starch, nutrients such as protein, dietary fiber, and minerals are removed. In addition to nutritional imbalance, rich nutrients have an impact on the environment. The object of research is Areca taro, a starch-rich agricultural product.

The research aims to use spray drying technology to obtain a whole betel nut taro powder for food processing, such as sausages and noodles. The taro is used as a raw material, and the whole taro flour is obtained after peeling, cutting, crushing with water, and spray drying. Using single factor and orthogonal experiment to optimize the spray drying process parameters and embedding agent of taro powder, and then analyze its physical and chemical properties.

The results show that adding $0.01 \%$ Xanthan gum $+0.12 \%$ Microcrystalline cellulose (embedded agent) to the taro emulsion can increase the extraction rate of taro flour, speed up the drying speed, and prevent sticking to the wall. The best process of spray drying: the speed of atomizer was $16000 \mathrm{r} / \mathrm{m}$, the wind temperature was $200{ }^{\circ} \mathrm{C}$, the material liquid concentration was $28.00 \%$ and the feeding rate was $75 \mathrm{~mL} / \mathrm{min}$. The taro powder produced by this process has better liquidity, light purple color, smooth texture, and strong flavor of taro. Product parameters: powder fluidity was $13.9 \mathrm{~cm}$, extraction rate was $15.36 \%$, water activity was 0.416 , chromaticity parameters were 19.73 ( $L^{*}$ value), 2.96 ( $a^{*}$ value) and 3.25 ( $b^{*}$ value), bulk density was $0.44 \mathrm{~g} / \mathrm{mL}$.

This technology can provide data support and reference for food processing companies. The taro whole powder would be widely used as food ingredients in future.

Keywords: taro powder, microcrystalline cellulose, spray drying, powder extraction rate, process parameters.

Shang, F., Kryzhska, T., Duan, Z. (2021). Study on the optimization of spray drying process for Areca taro powder with microcystalline cellulose. Technology Audit and Production Reserves, 6 (3 (62)), 39-42. doi: http://doi.org/10.15587/2706-5448.2021.242333

\section{Introduction}

High-fat diet increases the risk of several diseases, such as obesity, hyperlipidemia, hypertension, stroke, myocardial infarction, and coronary heart disease [1]. The use of high cellulose and starch content of raw materials to replace fat to produce low-fat food is very concerned [2]. Whole grains are considered to be good for blood sugar regulation [3]. More and more scholars are paying attention to whole grains and the consumption of whole grains is part of the national dietary recommendations $[4,5]$.

Areca taro is a perennial crop of Araceae, which grows underground and weighs $1-1.5 \mathrm{~kg}$. The main production area is in Guangxi Province, Guangdong Province, Hunan Province and Fujian Province of South China. The yield per hectare is $30000-45000 \mathrm{~kg}$. It has rough skin, red and purple lines inside the tuber, contains a lot of starch and dietary fiber, and produces special aroma after cooking. In the processing field, areca taro can be processed into taro chips, fried taro chips, frozen taro chips, Taro canned, Taro Milk Tea and other products [6]. However, at present, there are few public reports about the powder. It contains more starch and dietary fiber, and can be used as food supplement to sausage, bread and other products.
Spray drying is a common method of drying materials. After the solution or milky material is atomized, in the contact with the hot air, the moisture quickly vaporizes, and the dry product is directly obtained. Authors of research [7] using microencapsulation strategy enhanced the thermal stability of the phytochemicals and rendered biocompatible and biodegradable products of which the nutraceutical and cosmeceutical application may have potential. Authors of [8] used cellulose nanofibers to be added to a solution containing ginger essential oil and spray-dried technology to prepare particles, which can better protect essential oils. Authors of papers [9-11] used spray drying technology to study the whole sweet potato, purple potato and Yam powder and obtained the best drying process.

Thus, the object of research is Areca taro, a starch-rich agricultural product. The aim of research is to use spray drying technology to obtain a whole betel nut taro powder for food processing, such as sausages and noodles.

\section{Methods of research}

In this study, the characteristic fruit and vegetable Areca taro of south China was used as the experimental material. Firstly, the Areca taro was peeled, sliced, boiled 
and beaten, and then the whole Areca taro powder was generated by spray drying technology. The powder has rich flavor, light red color and high nutritional value, which is convenient for storage and transportation.

The test materials were fresh, pest-free, putrefaction free, surface damage free, and mature areca taro. Food processing accessories include Xanthan gum, Carrageenan, Arabic gum. The areca taro is cleaned, dried, skinned, cut, scalded, blanched, grayed, blended, homogenized, spray dried and sifted.

The taro power was made using the airflow spray dryer (Centrifugal air spray dryer, DFRP-5 Model, Dafeng Spray Drying Equipment Co., Ltd. Wuxi city, China). dosage:

Single factor experimental design of embedding agent

Xanthan gum $0.01 \%, 0.01 \%$ Xanthan gum $+0.6 \%$

Microcrystalline cellulose MC (0.9\%, $1.2 \%, 1.5 \%)$;

- At the same time, the working parameters of the

spray dryer: material liquid concentration $28 \%$, air

inlet temperature $180{ }^{\circ} \mathrm{C}$, feed speed $40 \mathrm{~mL} / \mathrm{m}$, the speed of atomizer is $20000 \mathrm{r} / \mathrm{min}$;

- Design feed speed parameters $(25,45,65,85 \mathrm{~mL} / \mathrm{min})$;

- Design feed wind temperature parameters $(150,170$ 190, $\left.210^{\circ} \mathrm{C}\right)$;

- Design material and liquid concentration parameters $(25 \%, 30 \%, 35 \%, 40 \%)$;

- Design speed of atomizer parameters (12000, 15000, $18000,21000 \mathrm{r} / \mathrm{min}$ ).

Select the best result of the single factor test, and use the orthogonal test to optimize the spray drying parameters (Feed rate, Wind temperature, Material liquid concentration, Atomizer speed). The orthogonal test is shown in Table 1.

Table 1

Factor and level of orthogonal test of spray drying of areca taro powder

\begin{tabular}{|c|c|c|c|c|}
\hline \multirow[b]{2}{*}{ Level } & \multicolumn{4}{|c|}{ Factor } \\
\hline & $\begin{array}{c}\text { Atomizer } \\
\text { speed, r/min }\end{array}$ & $\begin{array}{l}\text { Feed rate, } \\
\mathrm{mL} / \mathrm{min}\end{array}$ & $\begin{array}{l}\text { Wind tem- } \\
\text { perature, }{ }^{\circ} \mathrm{C}\end{array}$ & $\begin{array}{l}\text { Material liquid con- } \\
\text { centration, \% }\end{array}$ \\
\hline 1 & 16000 & 55 & 180 & 22 \\
\hline 2 & 18000 & 65 & 190 & 25 \\
\hline 3 & 20000 & 75 & 200 & 28 \\
\hline
\end{tabular}

Calculation method of taro powder extraction rate:

$$
\operatorname{PER}(\%)=\frac{P W}{T S C+E M} \cdot 100,
$$

where $P E R$ - powder extraction rate; $P W$ - power weight; $T S C$ - total solid content before spray drying; $E M-$ Embedding agent.

Refer to $[12,13]$ to determine the fluidity of taro powder. Fix the funnel to keep it vertical. The height of the funnel mouth $(1 \mathrm{~cm}$ in diameter) from the table top is about $8 \mathrm{~cm}$. Put a piece of clean white paper, add $40 \mathrm{~g}$ of taro powder from the funnel, measure the bottom diameter of the cone formed by the taro powder on the white paper, and use the diameter to determine the fluidity of the taro powder. The larger the diameter, the fluidity of taro powder is better. The bulk density measurement is to scatter the taro powder into a $10 \mathrm{~mL}$ measuring cylinder, measure the weight of $10 \mathrm{~mL}$ taro powder, and calculate the bulk density.

\section{Research results and discussion}

The embedding agent can increase the specific surface area and fluidity of the powder, which is conducive to the collection of the product. The effect of the embedding agent on the extraction rate of taro powder is shown in Table 2. The results of the study showed that the powder extraction rate and wall adhesion of the test group were better than those of the blank group, and $0.01 \%$ Xanthan gum $+1.2 \% \mathrm{MC}$ was more effective as an embedding agent. Authors of [14] used gum arabic, maltodextrin and whey protein concentrate as drying aids to spray-dry honey powder, and the powder recovery rate, solubility and dispersibility increased significantly $(p<0.05)$. Therefore, when preparing taro powder by spray drying, $0.01 \%$ Xanthan gum $+1.2 \%$ MC can be added as an embedding agent to improve the drying speed and prevent wall sticking.

Table 2

Effect of microcrystalline cellulose(MC) on spray drying of taro powder

\begin{tabular}{|l|c|c|l|}
\hline Embedding medium & $\begin{array}{c}\text { Water } \\
\text { activity, } \\
\text { Aw }\end{array}$ & $\begin{array}{c}\text { Powder } \\
\text { extraction } \\
\text { rate, \% }\end{array}$ & \multicolumn{1}{|c|}{ Sensory quality } \\
\hline Blank & 0.4435 & 11.95 & Sticking material \\
\hline $0.01 \%$ Xanthan gum & 0.4388 & 14.39 & Almost no wall sticking \\
\hline $\begin{array}{l}0.01 \% \text { Xanthan } \\
\text { gum + 0.6 \% MC }\end{array}$ & 0.4402 & 13.23 & Almost no wall sticking \\
\hline $\begin{array}{l}\text { 0.01 \% Xanthan } \\
\text { gum + 0.9 \% MC }\end{array}$ & 0.4396 & 14.48 & Almost no wall sticking \\
\hline $\begin{array}{l}0.01 \% \text { Xanthan } \\
\text { gum + 1.2 \% MC }\end{array}$ & 0.4374 & 14.91 & No wall sticking \\
\hline $\begin{array}{l}0.01 \% \text { Xanthan } \\
\text { gum + 1.5 \% MC }\end{array}$ & 0.4371 & 14.87 & Almost no wall sticking \\
\hline
\end{tabular}

The inlet air temperature is one of the important factors affecting the spray drying effect. As the inlet air temperature increases, the powder extraction rate of the treatment group increases (Table 3 ). The powder extraction rate of the treatment group with the inlet air temperature of $190{ }^{\circ} \mathrm{C}$ was the highest $13.65 \%$ and the water activity was relatively low. The brightness $L^{*}$ value of taro power first deepens and then becomes brighter with the increase of the inlet air temperature. The inlet air temperature of $210{ }^{\circ} \mathrm{C}$ has a great influence on the red $a^{*}$ value, which is only 2.89 , which is significantly lower than other temperatures $(p<0.05)$. This may be due to the influence of high temperature on the chromophore, which makes the taro powder appear more white. Comprehensive evaluation of the powder extraction rate, color and water activity parameter values, $190{ }^{\circ} \mathrm{C}$ is selected as the air inlet temperature of the spray drying of the whole taro powder.

Table 3

Areca taro powder Aw, Color and Powder extraction rate were affected by different inlet air temperature

\begin{tabular}{|c|c|c|c|c|c|}
\hline \multirow{2}{*}{$\begin{array}{c}\text { Inlet air tem- } \\
\text { perature, }\end{array}{ }^{\circ} \mathrm{N}$} & Water ac- & \multirow{2}{*}{$\begin{array}{c}\text { Powder extrac- } \\
\text { tivity, Aw }\end{array}$} & \multicolumn{3}{|c|}{ Colour } \\
\cline { 4 - 6 } & tion rate, \% & $L^{*}$ & $a^{*}$ & $b^{*}$ \\
\hline 150 & 0.4324 & 12.70 & 17.78 & 3.47 & 1.74 \\
\hline 170 & 0.4268 & 12.47 & 18.83 & 3.38 & 1.88 \\
\hline 190 & 0.4197 & 13.65 & 20.36 & 3.50 & 2.08 \\
\hline 210 & 0.3947 & 13.49 & 21.58 & 2.89 & 2.24 \\
\hline
\end{tabular}


The feeding speed also determines the drying effect. The test results (Table 4) showed that when the feeding speed was $25 \mathrm{~mL} / \mathrm{min}$, the water activity was lower, the drying was more complete, the $L^{*}$ value was higher, the brightness was higher, but the $A^{*}$ value was lower, and the purple color of taro was lighter. When the feeding speed is $85 \mathrm{~mL} / \mathrm{min}$, the powder rate was only $10.86 \%$, water activity increases, $a^{*}$ value was larger and tends to red, but the wall sticking phenomenon was serious and liquid droplets flow down from the inner wall of the dryer. The feed rate is an important factor that affects the output. In summary, the $65 \mathrm{~mL} / \mathrm{kg}$ feed rate was taken as the optimal parameter.

The centrifugal speed determines the effect of liquid atomization. The results of the treatment group (Table 5) show that the centrifugal speed is greater than $15000 \mathrm{r} / \mathrm{min}$, and the powder extraction rate is obviously improved. With the increase of the speed, the powder extraction rate continues to increase, and the powder extraction rate is the highest at $18000 \mathrm{r} / \mathrm{min}$. The powder extraction rate is $13.83 \%$. The water activity decreases with the increase of the powder extraction rate, indicating that the drying is more adequate; the color difference is not obvious. It can be seen that the centrifugal speed has a significant effect on the powder extraction rate and the degree of drying, and the spray drying process for the whole powder of taro is the best when the centrifugation is turned to $18000 \mathrm{r} / \mathrm{min}$.

Table 4

Areca taro Aw, Color and Powder extraction rate were affected by different inlet feed speed

\begin{tabular}{|c|c|c|c|c|c|}
\hline \multirow{2}{*}{$\begin{array}{c}\text { Inlet feed } \\
\text { speed, mL/min }\end{array}$} & \multirow{2}{*}{$\begin{array}{l}\text { Water ac- } \\
\text { tivity, Aw }\end{array}$} & \multirow{2}{*}{$\begin{array}{l}\text { Powder extrac- } \\
\text { tion rate, \% }\end{array}$} & \multicolumn{3}{|c|}{ Colour } \\
\hline & & & $L^{*}$ & $a^{*}$ & $b^{*}$ \\
\hline 25 & 0.3487 & 12.88 & 19.06 & 2.43 & 2.85 \\
\hline 45 & 0.3942 & 13.62 & 18.68 & 2.63 & 2.51 \\
\hline 65 & 0.4187 & 13.46 & 19.44 & 2.72 & 1.92 \\
\hline 85 & 0.4562 & 10.86 & 18.25 & 3.23 & 1.68 \\
\hline
\end{tabular}

Table 5

Areca taro Aw, Color and Powder extraction rate were affected by different centrifugal rotational speed

\begin{tabular}{|c|c|c|c|c|c|}
\hline \multirow{2}{*}{$\begin{array}{c}\text { Centrifugal } \\
\text { rotational speed, } \\
\text { r/min }\end{array}$} & \multirow{2}{*}{$\begin{array}{c}\text { Water activity, } \\
\text { Aw }\end{array}$} & \multirow{2}{*}{\begin{tabular}{|c|} 
Powder \\
extraction \\
rate, $\%$
\end{tabular}} & \multicolumn{3}{|c|}{ Colour } \\
\hline & & & $L^{*}$ & $a^{*}$ & $b^{*}$ \\
\hline 12000 & 0.424 & 10.85 & 19.64 & 3.37 & 2.03 \\
\hline 15000 & 0.419 & 12.96 & 19.80 & 3.58 & 2.27 \\
\hline 18000 & 0.401 & 13.83 & 19.46 & 3.26 & 2.45 \\
\hline 21000 & 0.388 & 13.68 & 18.55 & 3.08 & 2.76 \\
\hline
\end{tabular}

The concentration of the material liquid has a great influence on the spray output. A low concentration leads to high energy consumption and low output. A larger concentration will cause poor atomization and incomplete drying. The test results (Table 6) show that as the concentration of the feed liquid increases, the fluidity of the whole areca taro power becomes worse, but the bulk density increases. From the sensory state, it was found that the whole areca taro power sticks to the wall in the spray tower as the concentration of the feed increases. The degree of increase, $25 \%$ of the material liquid concentration has the phenomenon of wall sticking, and $40 \%$ of the material liquid concentration was very serious, indicating that the drying was insufficient. Comprehensive evaluation, a material liquid concentration of $25 \%$ was a better drying effect.

This study mainly investigates the effects of centrifugal speed, inlet air temperature, and material liquid concentration on the powder extraction rate, water activity, and color. Authors of [12] separately studied the effects of three drying aids, maltodextrin, $\beta$-cyclodextrin, and soluble starch on spray-dried strawberry powder, using fluidity, wettability, water content and color as evaluation indicators.

The results of the orthogonal test are shown in Table 7.

Taro powder Bulk density, Fluidity, Aw, Color and Powder extraction rate were affected by different material liquid concentration

Table 6

\begin{tabular}{|c|c|c|c|c|c|c|c|c|}
\hline \multirow{2}{*}{$\begin{array}{l}\text { Concentra- } \\
\text { tion, \% }\end{array}$} & \multirow{2}{*}{$\begin{array}{l}\text { Bulk density, } \\
\mathrm{g} / \mathrm{mL}\end{array}$} & \multirow{2}{*}{ Fluidity, cm } & \multirow{2}{*}{$\begin{array}{l}\text { Powder extrac- } \\
\text { tion rate, \% }\end{array}$} & \multirow{2}{*}{$\begin{array}{c}\text { Water activity, } \\
\text { Aw }\end{array}$} & \multicolumn{3}{|c|}{ Colour } & \multirow{2}{*}{ Sensory quality } \\
\hline & & & & & $L^{*}$ & $a^{*}$ & $b^{*}$ & \\
\hline 25 & 0.39 & 14.5 & 13.36 & 0.426 & 19.08 & 2.42 & 2.03 & Sticking material \\
\hline 30 & 0.42 & 14.1 & 12.78 & 0.435 & 18.64 & 2.81 & 2.18 & More of wall material viscosity \\
\hline 35 & 0.46 & 13.8 & 11.64 & 0.430 & 17.98 & 2.39 & 2.14 & More of wall material viscosity \\
\hline 40 & 0.50 & 12.7 & 9.96 & 0.461 & 17.43 & 3.38 & 2.64 & Severe wall material viscosity \\
\hline
\end{tabular}

Taro powder spray drying orthogonal experiment results

Table 7

\begin{tabular}{|c|c|c|c|c|c|c|}
\hline \multirow{2}{*}{ No. } & \multicolumn{4}{|c|}{ Factor } & \multirow{2}{*}{ Fluidity, cm } & \multirow{2}{*}{$\begin{array}{l}\text { Powder extrac- } \\
\text { tion rate, } \%\end{array}$} \\
\hline & A: Atomizer speed, r/min & B: Wind temperature, ${ }^{\circ} \mathrm{C}$ & C: Material liquid concentration, \% & $\mathrm{D}$ : Feed rate, $\mathrm{mL} / \mathrm{min}$ & & \\
\hline 1 & 1 & 1 & 1 & 1 & 11 & 14.84 \\
\hline 2 & 1 & 2 & 2 & 2 & 10.8 & 13.93 \\
\hline 3 & 1 & 3 & 3 & 3 & 11.2 & 15.48 \\
\hline 4 & 2 & 1 & 2 & 3 & 10.5 & 15.35 \\
\hline 5 & 2 & 2 & 3 & 1 & 10.8 & 12.48 \\
\hline 6 & 2 & 3 & 1 & 2 & 10.8 & 14.58 \\
\hline 7 & 3 & 1 & 3 & 2 & 10.8 & 15.08 \\
\hline 8 & 3 & 2 & 1 & 3 & 10.9 & 15.12 \\
\hline 9 & 3 & 3 & 2 & 1 & 10.7 & 12.85 \\
\hline$k_{1}$ & 33 & 32.3 & 32.7 & 32.5 & - & - \\
\hline$k_{2}$ & 32.1 & 32.5 & 32 & 32.4 & - & - \\
\hline$k_{3}$ & 32.4 & 32.7 & 32.8 & 32.6 & - & - \\
\hline$B$ & 0.9 & 0.4 & 0.8 & 0.2 & - & - \\
\hline \multicolumn{3}{|c|}{ Factor priority } & \multicolumn{4}{|c|}{$\mathrm{A}>\mathrm{C}>\mathrm{B}>\mathrm{D}$} \\
\hline \multicolumn{3}{|c|}{ Optimal combination } & \multicolumn{4}{|c|}{$\mathrm{A}_{1} \mathrm{~B}_{3} \mathrm{C}_{3} \mathrm{D}_{3}$} \\
\hline
\end{tabular}


The primary and secondary order that affects fluidity: the speed of atomizer $>$ the concentration of material liquid $>$ the inlet wind temperature $>$ the feed rate. The optimal combination of process parameters is $\mathrm{A}_{1} \mathrm{~B}_{3} \mathrm{C}_{3} \mathrm{D}_{3}$ that was the speed of atomizer was $16000 \mathrm{r} / \mathrm{m}$, the wind temperature was $200{ }^{\circ} \mathrm{C}$, the material liquid concentration was $28.00 \%$ and the feeding rate was $75 \mathrm{~mL} / \mathrm{min}$. Since there was no optimal combination in the orthogonal test, three verification tests were carried out under the optimal conditions. The results were averaged, and the yield of the whole powder of taro was $11.8 \mathrm{~cm}$. Compared with the data of the orthogonal test group, the yield was significantly increased, and the yield of the whole powder of taro was $0.6 \mathrm{~cm}$ higher than that of the optimal group. The inlet temperature was $200{ }^{\circ} \mathrm{C}$, the material flow rate was $60 \mathrm{~mL} / \mathrm{S}$, and the nozzle speed was $25000 \mathrm{r} / \mathrm{min}$, the best working parameters of strawberry powder can be obtained [12].

The spray drying process to produce taro powder has the advantage of fine products and can be used as ingredients for solid beverages, but the process is complex and energy consumption is high. The traditional hot air drying technology requires the taro to be sliced, dried, crushed, and sieved to obtain taro flour. Traditional technology has the advantages of large output and low energy consumption. The taro powder produced by two drying techniques can be used as ingredients for starchy sausages, noodles and biscuits.

\section{Conclusions}

Taro was used as raw material in this paper. Spray drying process parameters of taro whole powder and effects of embedding medium on taro whole powder drying were optimized by single factor and orthogonal experiment. The results showed that, adding $0.01 \%$ Xanthan gum $+1.2 \% \mathrm{MC}$ as embedding medium could improve taro whole powder yield, speed up flour drying and prevent wall sticking. The results show that adding $0.01 \%$ Xanthan gum $+1.2 \% \mathrm{MC}$ (embedded agent) to the taro emulsion can increase the extraction rate of taro flour, speed up the drying speed, and prevent sticking to the wall. The best process of spray drying: the speed of atomizer was $16000 \mathrm{r} / \mathrm{m}$, the wind temperature was $200{ }^{\circ} \mathrm{C}$, the material liquid concentration was $28.00 \%$ and the feeding rate was $75 \mathrm{~mL} / \mathrm{min}$. The taro powder produced by this process has better liquidity, light purple color, smooth texture, and strong flavor of taro. Product parameters: powder fluidity is $13.9 \mathrm{~cm}$, extraction rate is $15.36 \%$, water activity is 0.416 , chromaticity parameters are 19.73 ( $L^{*}$ value), 2.96 ( $a^{*}$ value) and 3.25 ( $b^{*}$ value), bulk density is $0.44 \mathrm{~g} / \mathrm{mL}$. The taro whole powder would be widely used as food ingredients in future.

The products obtained by spray drying are exquisite, small in particle size, hygienic and safe, and have high energy consumption, large investment and low production efficiency compared with hot air drying. Taro flour produced by spray drying and hot air drying can be used as food ingredients and added to sausages, noodles, milk tea, biscuits and other products.

\section{References}

1. Santhi, D., Kalaikannan, A., Malairaj, P., Arun Prabhu, S. (2015). Application of microbial transglutaminase in meat foods: A review. Critical Reviews in Food Science and Nutrition, 57 (10), 2071-2076. doi: https://doi.org/10.1080/10408398.2014.945990
2. Choi, Y.-S., Kim, H.-W., Hwang, K.-E., Song, D.-H., Jeong, T.-J., Kim, Y.-B. et. al. (2015). Effects of fat levels and rice bran fiber on the chemical, textural, and sensory properties of frankfurters. Food Science and Biotechnology, 24 (2), 489-495. doi: https://doi.org/10.1007/s10068-015-0064-5

3. Niu, M., Hou, G. G. (2018). Whole wheat noodle: Processing, quality improvement, and nutritional and health benefits. Cereal Chemistry, 96 (1), 23-33. doi: https://doi.org/10.1002/ cche. 10095

4. Food-based dietary guidelines - Austria. FAO. Available at: https://www.fao.org/nutrition/education/food-dietary-guidelines/regions/countries/austria/en/

5. Lin, S, Gao, J., Jin, X., Wang, Y, Dong, Z, Ying, J., Zhou, W (2020). Whole-wheat flour particle size influences dough properties, bread structure and in vitro starch digestibility. Food E Function, 11 (4), 3610-3620. doi: https://doi.org/ 10.1039/c9fo02587a

6. Zhiyin, C., Yihong, H., Chenzhong, J., Qiong, Z. D. W. (2012) Study on extraction process and performance of soluble dietary fiber from taro. Hunan Agricultural Sciences, 09, 89-91. doi: https://doi.org/10.16498/j.cnki.hnnykx.2012.09.008

7. De Souza, H. J. B., Dessimoni, A. L. de A., Ferreira, M. L. A. Botrel, D. A., Borges, S. V., Viana, L. C. et. al. (2020). Microparticles obtained by spray-drying technique containing ginger essential oil with the addition of cellulose nanofibrils extracted from the ginger vegetable fiber. Drying Technology, 39 (12), 1912-1926. doi: https://doi.org/10.1080/07373937. 2020.1851707

8. Carra, J. B., Matos, R. L. N. de, Novelli, A. P., Couto, R. O. do Yamashita, F., Ribeiro, M. A. dos S. et. al. (2022). Spraydrying of casein/pectin bioconjugate microcapsules containing grape (Vitis labrusca) by-product extract. Food Chemistry, 368, 130817. doi: https://doi.org/10.1016/j.foodchem.2021.130817

9. Dong, N., Wang, Q., Chen, Z., Lu, D., Deng, R. (2021). The effect of compound maltodextrin and $\beta$-cyclodextrin on the quality of spray-dried sweet potato powder. Food Industry Science and Technology, 07, 70-75. doi: https://doi.org/10.13386/ j.issn1002-0306.2020060224

10. Wang, Y., Gu, J., Qu, H. (2019). Study on the preparation of purple sweet potato powder by spray drying. Agricultural Science and Technology and Equipment, 01, 60-63. doi: https:// doi.org/10.16313/j.cnki.nykjyzb.2019.01.022

11. Zhang, L., Li, Q., Zhao, X., Shu, Q., Su, X., Xiong, X. (2017) Optimization of Spray Drying Technology in Processing Chinese Yam Flour. Packaging and Food Machinery, 5, 6-10. Available at: https://caod.oriprobe.com/articles/51755285/Optimization of Spray Drying Technology in Process.htm

12. Wang, Z., Fan, F., Wang, H., Wei, D., Wang, Y. (2006). The study on the processing parameters and formula of drying aid for strawberry powder. Science and Technology of Food Industry, 9, 117-119. Available at: http://caod.oriprobe.com/ articles/11400579/The_study_on_the_processing_parameters_ and formula of drying aid for s.htm

13. Alves, R. M. L., Grossmann, M. V. E., Silva, R. S. S. F. (1999) Gelling properties of extruded yam (Dioscorea alata) starch. Food Chemistry, 67 (2), 123-127. doi: https://doi.org/10.1016/ s0308-8146(99)00064-3

14. Suhag, Y., Nayik, G. A., Karabagias, I. K., Nanda, V. (2021) Development and Characterization of a Nutritionally Rich Spray-Dried Honey Powder. Foods, 10 (1), 162. doi: https:// doi.org/10.3390/foods10010162

Feifei Shang, Postgraduate Student, Department of Technology and Food Safety, Sumy National Agrarian University, Sumy, Ukraine; School of Food and Bioengineering, Hezhou University, Hezhou, China, ORCID: https://orcid.org/0000-0001-7648-9568

Tetiana Kryzhska, PhD, Senior Lecturer, Department of Techno$\log y$ and Food Safety, Sumy National Agrarian University, Sumy, Ukraine, ORCID: https://orcid.org/0000-0001-7151-9799

$\triangle$ Zhenhua Duan, School of Food and Bioengineering, Hezhou University, Hezhou, China,e-mail:dzh65@126.com, ORCID:https:// orcid.org/0000-0002-9283-3629

$\triangle$ Corresponding author 